\title{
UN LÍMITE A LA RESPONSABILIDAD DE LA EMPRESA PRINCIPAL EN EL PROCEDIMIENTO DE TUTELA LABORAL. COMENTARIO A SENTENCIA DE LA ILUSTRÍSIMA CORTE DE APELACIONES DE CONCEPCIÓN.
}

\author{
A LIMIT TO THE RESPONSIBILITY OF THE PRINCIPAL COMPANY IN \\ THE PROCEDURE OF LABOR GUARDIANSHIP. COMMENT TO \\ JUDGMENT OF THE MOST ILLUSTRIOUS COURT OF APPEALS OF \\ CONCEPTION.
}

\author{
RODRIGO SANHUEZA TORRES*
}

\begin{abstract}
RESUMEN: La responsabilidad de la empresa principal en el procedimiento de tutela laboral es un tema que sigue siendo discutido en nuestra jurisprudencia, existiendo esencialmente dos posturas: aquella que hace enteramente aplicable la responsabilidad solidaria/subsidiaria establecida por el artículo183-B y siguientes del Código del Trabajo, versus aquella que establece que las normas de subcontratación no tienen ninguna relación con el procedimiento de tutela laboral. La sentencia que se analiza en este artículo opta, mediante argumentos muy sólidos, por la segunda postura: que el artículo 183-B del Código del Trabajo no tiene aplicación para el procedimiento de tutela laboral. No obstante, en lo negativo, el fallo establece que la empresa principal no responde en este tipo de procedimientos inclusive teniendo injerencia en la vulneración de derechos fundamentales, lo que a mi parecer es erróneo.
\end{abstract}

Palabras Claves: tutela laboral, derechos fundamentales, empresa principal, responsabilidad solidaria, responsabilidad subsidiaria, articulo $183-B$.

ABSTRACT: The responsibility of the principal company in the procedure of labor guardianship is a topic that continues being discussed in our jurisprudence, existing essentially two positions: that one that makes the solidary responsibility entirely applicable established for artículo183-B and following of the Code of the Work, versus that one that establishes that the procedure of subcontracting do not have any relation with the procedure of labor guardianship. The judgment that is analyzed in this article chooses, by means of very solid arguments, for the second position: that the article 183-B of the Code of the Work does not have application for the procedure of labor guardianship. Nevertheless, in the negative thing, the failure establishes that the principal company does not answer in this type of procedures inclusive having interference in the violation of fundamental rights, which is to me erroneous.

Key words: Labor guardianship, fundamental rights, principal company, solidary responsibility, subsidiary responsibility, 183-B article-

\section{INTRODUCCIÓN:}

\section{SUBCONTRATACIÓN Y TUTELA LABORAL: JUNTOS PERO NO REVUELTOS}

La vorágine que ha significado para la doctrina laboral el proyecto de Reforma Laboral presentado por el Gobierno de la presidenta Michelle Bachelet ha causado que una fecha muy destacada para la legislación laboral chilena se tenga completamente descuidada: el 3 de enero del año 2016 se cumplen ya 10 años desde la publicación de la Ley $\mathrm{N}^{\circ}$ 20.087, la cual estableció en Chile la "Reforma Procesal Laboral", como comúnmente fue conocida en aquella época. El propósito de este artículo es precisamente evitar que tan insigne fecha pase rápidamente al olvido, a través de continuar

\footnotetext{
* Abogado de la Pontificia Universidad Católica de Chile y ayudante de los profesores Cecilia Sánchez y Fernando Arab. Diploma en Derecho del Trabajo y Seguridad Social de la Pontificia Universidad Católica de Chile. Contacto: rodrigo.sanhueza.t@gmail.com
} 
con el análisis de una de las más novedosas incorporaciones de aquella reforma: el procedimiento de tutela laboral.

El procedimiento de tutela laboral es la representación más efectiva en nuestro ordenamiento jurídico de la eficacia horizontal de los derechos constitucionales, es decir, de cómo aplicar en forma directa las normas constitucionales entre particulares. Si bien los derechos constitucionales por los cuales puede entablarse una acción de estas características se encuentran claramente delimitados ${ }^{1}$, y que la redacción de sus normas procedimentales no ha estado exenta de diferencias interpretativas entre litigantes ${ }^{2}$, es imposible negar que la creación de este procedimiento ha transformado la cultura de relaciones laborales en nuestro país, otorgándole a los trabajadores una herramienta sumamente concreta por la cual hacer valer sus derechos fundamentales, cuyas sanciones son conocidas y temidas por las empresas ${ }^{3}$. En palabras del profesor José Luis Ugarte, la consagración de este procedimiento le ha permitido al trabajador pasar de erizo, a zorro ${ }^{4}$, lo cual en materia de respeto de derechos fundamentales, es ciertamente positivo.

No obstante, el gran vacío que este procedimiento dejó, y que todavía deja, es que en él no existe ninguna referencia a los trabajadores que prestan servicios bajo régimen de subcontratación. En efecto, de revisar los artículos 485 y siguientes del Código, da la impresión que las normas de subcontratación no existían en aquella época, lo cual es efectivamente cierto, no existían, toda vez que la Ley $\mathrm{N}^{\circ} 20.123$ que estableció las normas sobre trabajo en régimen de subcontratación fue publicada 9 meses después de la Reforma Procesal Laboral, circunstancia que suele ser olvidada, pero que ciertamente ayuda a explicar la total desconexión existente entre ambos cuerpos normativos. Con motivo de lo anterior, la publicación de la Ley $\mathrm{N}^{\circ} 20.123$ causó el surgimiento de múltiples interrogantes acerca del procedimiento de tutela laboral, las cuales lamentablemente nunca fueron abordadas en la discusión legislativa sobre el trabajo en régimen de subcontratación: ¿Puede un trabajador subcontratado demandar también por tutela laboral a la empresa principal? ¿Atenúa la responsabilidad de la empresa principal el ejercicio de los derechos de información y retención? ¿Puede la empresa principal defenderse en un juicio negando su participación en los hechos, o su condición de empresa principal la obliga necesariamente a responder, tal como si se tratara del pago

\footnotetext{
${ }^{1}$ Los derechos susceptibles de accionar este procedimiento son los siguientes: derecho a la vida; derecho a la integridad física; derecho a la intimidad y respeto a la vida privada; derecho al honor; derecho a la inviolabilidad de toda forma de comunicación privada; derecho a la libertad de conciencia, la manifestación de las creencias y el libre ejercicio de todos los cultos; libertad de expresión, opinión e información sin censura previa, la libertad de trabajo y contratación laboral, libertad sindical y garantía de indemnidad.

2 A juicio personal, la mayor problemática resultó la acepción “con ocasión del despido" establecida por el artículo 489 del Código del Trabajo, toda vez que su interpretación literal dio a lugar a que muchos entendiesen que para dar curso a esta acción, la vulneración de derechos fundamentales debía ocurrir en el acto mismo de la terminación del contrato de trabajo, y no antes, lo cual ciertamente quitaba toda aplicación práctica a la norma, ya que son pocos los casos en que el empleador es tan torpe como para vulnerar derechos fundamentales en el proceso mismo del despido. Afortunadamente, y en una clara invocación al artículo 24 del Código Civil, nuestra judicatura la ha dado una interpretación bastante más amplia a este artículo, permitiendo que se conozcan hechos previos al despido, siendo todavía un tema en discusión hasta cuanto tiempo atrás puede el juez efectivamente retroceder.

${ }^{3}$ Dichas sanciones son, principalmente, las 6 y 11 remuneraciones extra en caso de despido, y muy especialmente, la prohibición de contratar con la Administración del Estado establecida en la ley de bases sobre contratos administrativos de suministro y prestación de servicios (ley $\mathrm{n}^{\circ}$ 19.886). Sobre esta última sanción y sus efectos, recomiendo ver la crítica hecha por LARA y HELFMANN (2012) "Tribunal Constitucional y Contratación Pública: Inhabilidades para Contratar con el Estado y Restricción de Libertades Económicas”. Sentencias Destacadas 2012. Libertad y Desarrollo. Páginas 151-173.

${ }^{4}$ UGARTE (2007) pp. 49-67
} 
de sueldos o de cotizaciones previsionales? La ley por lo menos, no dio, ni da todavía, alguna respuesta a estas interrogantes.

\section{POSICIONES JURISPRUDENCIALES PREVIAS A LA SENTENCIA EN ANÁLISIS}

En vista de que el trabajo en régimen de subcontratación y el procedimiento de tutela laboral fueron regulados obviando completamente el uno del otro, fue nuestra judicatura laboral quien debió de aclarar si es que la empresa principal, actuando en calidad de tal, debía de responder en un procedimiento de tutela laboral. Al respecto, considerando lo limitado de esta clase de juicios, y que la gran mayoría de los juicios laborales termina en acuerdo, es difícil hablar acerca de una posición jurisprudencial dominante en esta materia, dado los pocos casos de tutela laboral que efectivamente llegan a sentencia definitiva. No obstante, sí es posible destacar dos líneas jurisprudenciales sobre el tema en cuestión:

a) La empresa principal SÍ debe de responder en un procedimiento de tutela laboral, por aplicación de las normas de trabajo en régimen de subcontratación.

La primera posición jurisprudencial establece que en un procedimiento de tutela laboral la empresa principal debe de responder, toda vez que en esta materia la normativa sobre subcontratación resulta plenamente aplicable, aun cuando, según ya hemos revisado, existe una absoluta desconexión legal entre ambas. No obstante, tribunales como la Iltma. Corte de Apelaciones de Santiago optaron por interpretar el artículo 183-B del Código del Trabajo de manera amplia, según se puede desprender del siguiente extracto de sentencia:

"7) Que el recurso de autos denuncia, como ya se indicó, la infracción de una única norma legal, cual el articulo 183 B del Código Laboral, que es del siguiente tenor: "La empresa principal será solidariamente responsable de las obligaciones laborales y previsionales de dar que afecten a los contratistas a favor de los trabajadores de éstos, incluidas las eventuales indemnizaciones legales que correspondan por término de la relación laboral. Tal responsabilidad estará limitada al tiempo o periodo durante el cual el o los trabajadores prestaron servicios en régimen de subcontratación para la empresa principal". Se trata, como puede apreciarse, de una norma legal de amplio alcance, y los términos generales en que se encuentra redactada permite perfectamente aplicarla a un caso como el de la especie, por lo que no existe la infracción legal que se denuncia, cuando se la ba interpretado en un determinado sentido"'.

Cuesta encontrarle sentido a esta interpretación legal que no sea la aplicación ciega del principio protector y el de la ajenidad del trabajador subcontratado ${ }^{6}$, lo cual queda del todo demostrado mediante la siguiente sentencia que, inexplicablemente, fundamenta la responsabilidad de la empresa principal en el artículo 183-B del Código del Trabajo:

"Decimoquinto: Que además resulta lógico que la principal responda de este tipo de indemnizaciones por cuanto se ha aprovechado de los servicios de los trabajadores de la contratista sin ser considerada empleadora, por lo que $\underline{\mathrm{su}}$ responsabilidad (solidaria o subsidiaria) viene a ser la moneda de cambio de esta concesión legal que lo libera del peso

\footnotetext{
${ }^{5}$ Lara con Agrícola Concha y Toro (2011).

${ }^{6}$ Por ajenidad entendemos que que el trabajador presta sus servicios por cuenta de su empleador, quien asume los riesgos del trabajo y se hace dueño de los frutos que éste genera
} 
que significa administrativamente tener todos los trabajadores a su cargo, estando además en una inmejorable situación de subrogarse de los derechos del trabajador para repetir contra la contratista".

Como puede apreciarse, esta interpretación simplemente pareciera buscar favorecer al trabajador por un aspecto más fáctico que legal, cual es: que la empresa principal cuenta con más patrimonio que la empresa contratista, y por lo tanto, le asegura al trabajador afectado una mayor posibilidad de pago $^{8}$. No obstante, desde un punto de vista estrictamente jurídico, la presente línea jurisprudencial carece de mayor sustento, toda vez que el contenido del artículo 183-B del Código del Trabajo dista enormemente de incluir una indemnización como la que establece el artículo 489 del mismo cuerpo legal, según pasaremos a revisar. Confirma la confusión el hecho de que muchas de las sentencias de esta línea jurisprudencial afirman que la empresa principal responde subsidiariamente en caso de ejercer sus derechos de información y retención ${ }^{9}$, en circunstancias de que dicha facultad no se relaciona en nada con la vulneración de derechos fundamentales, ni tampoco ayuda a prevenir la existencia de las mismas.

b) La empresa principal NO debe de responder en un procedimiento de tutela laboral, toda vez que las normas sobre subcontratación no resultan aplicables en dicho procedimiento.

La segunda postura es absolutamente inversa a la anterior: la empresa principal no responde en el procedimiento de tutela laboral porque las normas de subcontratación no tienen aplicación en este procedimiento. Si bien no comparto íntegramente esta posición, toda vez que no me parece correcto señalar que la empresa principal nunca debe de responder en este tipo de procedimientos ${ }^{10}$, sí me parece que la presente posición está muchísimo mejor fundada que la anterior, y que efectivamente toca un punto que es absolutamente correcto, cual es, el que la empresa principal no tiene que responder por aplicación de las normas sobre subcontratación.

Respecto a esta posición jurisprudencial, existe una sentencia que la ejemplifica de muy buena manera, la cual pasó a citar a continuación:

"Vigésimo Tercero: Que, en cuanto a la pretensión de condenar solidariamente a Sky Line a las pretensiones demandadas en denuncia de vulneración de derechos fundamentales, esta debe ser rechazada, toda vez, que en primer lugar el vulnerar derechos fundamentales es un actuar personal y directo de responsabilidad únicamente de quien realiza los actos vulneratorios y segundo de conformidad a las normas de subcontratación la responsabilidad de la empresa mandante sólo dice relación con obligaciones laborales y previsionales, que se generan como consecuencia de la prestación de servicios en los términos del artículo 7 del Código del Trabajo y no como sanción a ilícitos laborales" "1.

En mi opinión, esta sentencia (en adelante "fallo Skyline") resulta particularmente destacable, toda vez que establece dos principios que considero fundamentales en esta materia: primero, que la

\footnotetext{
${ }^{7}$ Lara con Agrícola Concha y Toro (2011).

${ }^{8}$ En este sentido, Alejandro Castelló señala que se justifica el traslado de riesgos económicos y laborales a la empresa principal, toda vez que ésta "se presume más fuerte y solvente". Más información en CASTELLO, Alejandro. "La Subcontratación y las Relaciones de Trabajo” en Uruguay. Revista Latinoamericana de Derecho Social Núm. 9, juliodiciembre de 2009. Página 82.

9 Al respecto, ver causa "Lara con Chiyong" (2010).

$10 \mathrm{Al}$ respecto, hace ya 3 años, esta revista me dio la oportunidad de tratar profundamente la materia en cuestión, por lo que evidentemente recomiendo dicho artículo para un análisis más profundo al respecto. Dicho artículo fue publicado en la Revista Chilena de Derecho del Trabajo y de la Seguridad Social, Volumen 3, N 5, año 2012. Páginas 93-112.

${ }_{11}$ Peña con Constructora e Inmobiliaria Casa Grande Limitada (2010).
} 
vulneración de derechos fundamentales es un actuar personal cuya responsabilidad debe ser personalísima; y segundo, que la sanción establecida por el artículo 489 del Código del Trabajo excede al concepto de "obligaciones laborales y previsionales" establecido por el artículo 183-B del mismo cuerpo legal.

\section{SENTENCIA DE LA ILUSTRÍSIMA CORTE DE APELACIONES DE CONCEPCIÓN}

Los hechos que fundamentan el recurso de nulidad en análisis son los siguientes: una ex trabajadora de la empresa Team Work Recursos humanos interpuso una demanda de tutela laboral con ocasión del despido en contra Team Work Recursos Humanos, y conjuntamente en contra de Telefónica Chile S.A. y Telefónica Móviles Chile S.A, al estimar que todas esas empresas debían de ser consideradas como su empleadora, solicitando de manera subsidiaria, que se declarase que ella trabajó en régimen de subcontratación para las dos últimas empresas.

El fundamento de la tutela laboral es el maltrato psicológico que sufrió la trabajadora por parte de supervisores de todas las sociedades demandadas, al punto de caer en cuadros depresivos y una parálisis fácil a raíz de dicho maltrato, afirmando la trabajadora que ella no fue despedida por las razones señaladas en su carta de despido, sino que por la mala imagen que podía generar para todas estas empresas el contar dentro de su staff con una trabajadora con sus problemas de salud, lo cual constituía para ella una vulneración a su dignidad y a su integridad psicológica. En virtud de lo anterior, solicitó el pago de las 11 remuneraciones descrita por el artículo 489 del Código del Trabajo, más el pago de $\$ 30.000 .000$ a título de daño moral.

La sentencia en primera instancia, dictada por el Juzgado de Letras del Trabajo de Los Angeles ${ }^{12}$, estableció que todas las demandadas efectivamente eran empleadoras de la trabajadora, $\mathrm{y}$ que todas ellas vulneraron sus derechos fundamentales, condenándolas a pagar todas las sumas adeudadas proveniente del despido injustificado, más los recargos correspondientes y la sanción adicional de 11 remuneraciones mensuales establecida por el artículo 489 del Código del Trabajo. No obstante, la petición de daño moral fue rechazada, al estimar el Tribunal que la indemnización del artículo 489 del Código del Trabajo constituye una compensación de daño moral prefijada por la ley, por lo que la indemnización por daño moral sería incompatible con las remuneraciones establecidas en el artículo antedicho.

Una vez que las demandadas recurrieron de nulidad, las empresas Telefónica Chile S.A. y Telefónica Móviles Chile S.A obtuvieron un fallo favorable por parte de la Ilustrísima Corte de Apelaciones de Concepción, acogiéndose dicho recurso de nulidad, y obteniendo en consecuencia una sentencia de reemplazo. Dicha sentencia de reemplazo estableció que ambas empresas no eran empleadoras de la trabajadora, sino que solo mantuvieron con ella una relación de subcontratación. En lo que respecta a su responsabilidad, el fallo resuelve que están absueltas de responder por las vulneraciones de derechos fundamentales, estableciendo unos considerandos realmente notables en lo que respecta a su responsabilidad, los cuales conviene evaluar en profundidad:

DECIMOCTAVO: Que el Articulo 183-B del Código del Trabajo establece que "La empresa principal será solidariamente responsable de las obligaciones laborales y previsionales de dar que afecten a los contratistas en favor de los trabajadores de éstos, incluidas las eventuales indemnizaciones legales que correspondan por término de la relación

12 Rupayan con Team Work Recursos Humanos Ltda. (2014). 
laboral. Tal responsabilidad estará limitada al tiempo o período durante el cual el o los trabajadores prestaron servicios en régimen de subcontratación para la empresa principal." A la luz de la norma legal transcrito es preciso establecer si ella alcanza a la vulneración de los derechos fundamentales de los trabajadores.

DECIMONOVENO: Que respecto de las obligaciones de dar con carácter laboral y previsional, la opinión prácticamente unánime de la doctrina y jurisprudencia es que dichas obligaciones se refieren remuneraciones, asignaciones en dinero, cotizaciones previsionales e indemnizaciones legales por término del contrato de trabajo. Podría aceptarse la solidaridad de la empresa principal en el pago de las indemnizaciones por tutela laboral cuando la obligación nace, como en este caso, de un procedimiento de tutela por despido; sin embargo, el artículo 183-B ya referido es claro en cuanto disponer que tal condena solidaria procede sólo en el pago de las indemnizaciones legales con ocasión del término de un contrato de trabajo, sin referirse a las sanciones por vulneración de derechos, omisión realizada precisamente porque las indemnizaciones por término del contrato de trabajo y las sanciones por vulneración de derechos fundamentales tienen una naturaleza jurídica distinta. La indemnización legal por término del contrato de trabajo es una suma de dinero que debe pagarse al trabajador en los casos en que el empleador lo despide por alguna de las causales establecidas en el artículo 161 del Código del Trabajo, si es que el contrato de trabajo ha estado vigente durante un año o más. Dicho pago no tiene la naturaleza jurídica de una sanción para el empleador, toda vez que éste es un mecanismo contemplado en la legislación laboral para atenuar los perjudiciales efectos que tiene para el trabajador perder su fuente de ingresos, no siendo el comportamiento del empleador la razón por la cual el trabajador tiene el derecho de recibir este pago. Por otra parte, el pago que contempla el artículo 489 del Código del Trabajo es una sanción para aquellos sujetos que vulneran ciertas garantias constitucionales del trabajador, en donde el pago opera como una compensación que se le bace al trabajador por el menoscabo sufrido y una sanción al empleador por su conducta, independientemente de que en ciertos casos dicha sanción proceda en conjunto con una indemnización por término de contrato de trabajo.

VIGESIMO: Que, en resumen, del tenor literal del artículo 183-B del Código del Trabajo, podemos desprender que la empresa principal no tiene responsabilidad alguna por la vulneración a los derechos fundamentales de la empresa contratista, al no contemplar este articulo las hipótesis de responsabilidad que establece el procedimiento de tutela de derechos fundamentales" $"$.

En efecto, la sentencia es tan notable porque señala una razón muy potente para establecer que la empresa principal no debe de responder de un procedimiento de tutela laboral cuando el fundamento invocado es la normativa referente a subcontratación: el artículo 183-B del Código del Trabajo no incluye la sanción establecida por el artículo 489 del mismo cuerpo legal, toda vez que ésta última es una sanción legal, y no una indemnización.

Desafortunadamente, si bien esta sentencia es sumamente importante, tanto por tratarse de una sentencia emanada de un Tribunal Superior de Justicia como por la precisión de sus términos, en mi opinión se quedó corta en sus argumentos, toda vez que justifica toda su decisión en la conceptualización de que lo dispuesto por el artículo 489 es una sanción y no una indemnización, en circunstancias que hay otros dos argumentos igualmente validos para justificar esta línea jurisprudencial, los cuales son:

- Que el ejercicio de los derechos de información y retención por parte de la empresa principal en nada ayudan a prevenir una vulneración de derechos fundamentales, por lo que castigar a la empresa principal producto de las normas sobre subcontratación significa situar a la

${ }^{13}$ Rupayan con Team Work Recursos Humanos Ltda. (2015). 
empresa principal en una hipótesis de responsabilidad objetiva, en circunstancias de que nuestro ordenamiento jurídico establece este tipo de responsabilidad solo excepcionalmente y mediante texto expreso.

- Que la empresa principal solo debe responder de las obligaciones laborales y previsionales de dar, en circunstancias de que la sanción establecida por el artículo 489 del Código del Trabajo proviene de una obligación de no hacer (no vulnerar derechos fundamentales)

De todas formas, en tiempos en donde la postura en materia laboral de los Tribunales Superiores de Justicia pareciera estar absolutamente inclinada hacia el lado de una de las partes, según lo ha señalado sin ningún tapujo uno de los ministros de la Corte Suprema que suele presidir la sala laboral ${ }^{14}$, ciertamente se agradecen fallos como el analizado, el cual construye la solución a la controversia desde la normativa legal, y no al revés, como lamentablemente tantas veces toca ver, en que la solución a la controversia viene en forma previa al análisis normativo, quedando este último como un instrumento para justificar la solución ya alcanzada. Un buen ejemplo de ello es, precisamente, la primera línea jurisprudencial analizada en este artículo.

\section{LA PROBLEMÁTICA DEL ACCESO A LA TUTELA LABORAL PARA LOS TRABAJADORES SUBCONTRATADOS}

Si bien el fallo en análisis me parece sumamente destacable, toda vez que considero que analiza correctamente la desconexión legal entre la normativa que regula la subcontratación y la que establece el procedimiento de tutela laboral, paradojalmente, no estoy de acuerdo con la solución de fondo a la cual arriba, toda vez que, en atención a que la Corte dejó establecida la participación de trabajadores de las empresas principales en la vulneración de derechos fundamentales de la demandante, dichas empresas debieron haber sido efectivamente sancionadas. El motivo de mi discrepancia con esta sentencia es que ésta omite un elemento clave que sí es recogido por el fallo Skyline: que la responsabilidad en esta materia debe ser de carácter personalísima.

En efecto, mi posición en este asunto no es que la empresa principal no debe de responder nunca en un procedimiento de tutela laboral, sino que no debe de hacerlo en base a la normativa sobre subcontratación, lo cual es sumamente distinto. Así, dado que en el caso de autos quedó plenamente acreditado la participación de las empresas principales en los actos vulneratorios, éstas debieron de haber sido sancionadas, mas no por el comportamiento de un tercero (su contratista), sino que por su propio comportamiento. Precisamente, el problema que trae consigo la aplicación total de esta sentencia, es que nos lleva a lo que la profesora Marcela Díaz ha señalado muy acertadamente como "la encrucijada procedimental de los trabajadores subcontratados" 15 .

\footnotetext{
14 "Yo estoy aquí para defender al trabajador en materia laboral, porque el derecho laboral es tutelar de la parte más débil, es un derecho de fuero y eso no lo callo" Ministro Carlos Cerda, en seminario organizado por la propia Corte Suprema denominado "Los derechos fundamentales y la Eficacia Directa en el derecho laboral nacional: la experiencia italiana y chilena". Más información en http://www.elmostrador.cl/noticias/pais/2015/07/30/presidente-de-la-suprema-hace-crudodiagnostico-de-la-realidad-laboral-en-chile-y-critica-esquema-neoliberal-que-la-rige/

15 DÍAZ (2015) pp. 65-66.
} 
Dicha encrucijada se produce porque, producto de la desconexión legal entre la tutela laboral y subcontratación, las normas procedimentales de la tutela laboral se aplican solo para el empleador ${ }^{16}$, y no así para la empresa principal, por lo que bajo la lógica que confirma la Ilustrísima Corte de Apelaciones de Concepción, la empresa principal no tendría que responder en un procedimiento de tutela laboral aun cuando sí haya tenido participación en los hechos vulneratorios, lo cual deja a la empresa principal en un plano de impunidad que no me parece adecuado ni tampoco ajustado al espíritu general de la legislación. ${ }^{17}$

Para subsanar esta problemática, podría pensarse que, dado que lo sancionado por el artículo 485 del Código del Trabajo es la vulneración de derechos fundamentales cometidos "en el ejercicio de las facultades del empleador", la empresa principal sí podría ser incluida en las sanciones establecidas por el procedimiento de tutela laboral, en la medida que ésta se arrogase facultades propias del empleador. No obstante, la acepción antedicha es sumamente difusa, tan difusa como la línea que determina que un trabajador subcontratado está subordinado a su empleador y no a la empresa principal, por lo que me parece que dicha solución más podría oscurecer que aclarar el tema.

En mi opinión, en casos en donde la empresa principal sí participa de actos vulneratorios de derechos fundamentales, ésta debiese de responder por el daño moral causado en base a las normas generales de la responsabilidad extracontractual, toda vez que, dado que la empresa principal está exenta de las reglas procedimentales del proceso de tutela laboral, el artículo 489 del Código del Trabajo no tendría aplicación, por lo que no podría haber incompatibilidad alguna entre ambas compensaciones. ${ }^{18}$ Precisamente, lo que lamento del fallo en análisis es que el Tribunal optó por rechazar la indemnización por daño moral en contra de las empresas principales por una supuesta incompatibilidad con el artículo 489, en circunstancias que, según ya vimos, dicho artículo no se le aplica a la empresa principal. Ese fue el paso que, en mi opinión, la Corte de Apelaciones de Concepción no estuvo dispuesta a dar, lo que no quita que el fallo en si mismo represente un enorme progreso en materia de respeto a la legislación laboral vigente. Faltaría solo dar ese último paso, que espero, finalmente se llegue a dar.

\section{BIBLIOGRAFÍA}

\footnotetext{
16 La mayoría de la doctrina efectivamente ha establecido que la aplicación de este procedimiento rige solo para el empleador. A modo meramente ejemplar: "la protección de los derechos fundamentales del trabajador establecida en este Código, a través de este procedimiento especial de tutela, sería en contra de las actuaciones ilicitas y lesivas del empleador", FERRADA y DİAZ (2011) p. 100.

${ }_{17} \mathrm{Al}$ respecto, la profesora Marcela Díaz es sumamente tajante al señalar que si la empresa principal vulnera derechos fundamentales de un trabajador contratista sencillamente: "no pasa nada", afirmando a su vez que en este momento, los trabajadores subcontratados se encuentran en materia de tutela laboral “en el más absoluto desamparo procesal”. Más en DÍAZ (2015) pp. 65-66.

18 En esta material, resulta sumamente importante reflexionar acerca de si las 6 a 11 remuneraciones establecidas por el artículo 489 corresponden a una indemnización por daño moral previamente fijado por la ley, o si dichas remuneraciones son solo una sanción, siendo perfectamente posible una sanción adicional por daño moral. Sin tener una posición definida en esta materia, ciertamente resulta del todo cuestionable que el legislador haya determinado que la indemnización que se le debe pagar a un trabajador por haber sido objeto de una vulneración de derechos fundamentales es intrínsecamente proporcional a la remuneración que ordinariamente recibe, toda vez que ello hace que la gravedad de dicha vulneración de dependa de cuanto ganaba el afectado, poniéndole así un precio a la dignidad humana. Sobre la discusión en cuestión, recomendamos el artículo escrito por el profesor GAMONAL (2012) pp. 161-176.
} 
CASTELLO, Alejandro (2009): "La Subcontratación y las Relaciones de Trabajo en Uruguay". Revista Latinoamericana de Derecho Social, N. 9, julio-diciembre, pp. 53-87.

DÍAZ, Marcela (2015): "La encrucijada procedimental de los trabajadores subcontratados. Tutela de derechos fundamentales". Revista Laboral Chilena, N²40, pp. 65-66.

FERRADA, Juan Carlos; DÍAZ, Rodolfo (2011): “La protección de los derechos fundamentales de los trabajadores en el nuevo procedimiento de tutela laboral". Revista Chilena del Derecho, vol. XXIV, No 2, pp. 91-111.

GAMONAL, Sergio (2012): "Evolución del daño moral por término del contrato de trabajo en el derecho chileno". Revista de Derecho de la Pontificia Universidad Católica de Valparaíso, vol. XXXIX, pp. 161-176.

LARA ARROYO, José Luis; HELFMANN MARTINI, Carolina (2012): "Tribunal Constitucional y Contratación Pública: Inhabilidades para Contratar con el Estado y Restricción de Libertades Económicas Disponible en $<$ http://lyd.org/wpcontent/uploads/2015/02/pp-151-173-Tribunal-Constitucional-y-contratacion-publicainhabilidades-para-contratar-con-el-Estado-JLLara-CHelfmann.pdf $>$

SANHUEZA, Rodrigo (2012). "La Responsabilidad de la Empresa Principal en el Procedimiento de Tutela Laboral". Revista Chilena de Derecho del Trabajo y de la Seguridad Social, vol. 3, $\mathrm{N}^{\circ}$ 5, pp. 93-112.

UGARTE CATALDO, José Luis (2007): "La Tutela de Derechos Fundamentales y el Derecho del Trabajo: de Erizo a Zorro". Revista de Derecho (Valdivia), VOL xx, n², pp. 4967.

\section{JURISPRUDENCIA}

Lara con Agrícola Concha y Toro (2011): Iltma. Corte de Apelaciones de Santiago, 5 de julio del 2011 (recurso de nulidad).

Rupayan con Team Work Recursos Humanos Ltda. (2015): Iltma. Corte de Apelaciones de Concepción, 10 de junio del 2015 (recurso de nulidad).

Lara con Agrícola Concha y Toro (2011): $2^{\circ}$ Juzgado de Letras del Trabajo de Santiago, 4 de marzo del 2011 (procedimiento de tutela laboral).

Lara con Chiyong (2010): $2^{\circ}$ Juzgado de Letras del Trabajo de Santiago, 19 de marzo del 2010 (procedimiento de tutela laboral).

Peña con Constructora e Inmobiliaria Casa Grande Limitada (2010): Juzgado de Letras del Trabajo de Calama, 26 de abril de 2010 (procedimiento de tutela laboral). 
REVISTA CHILENA DE DERECHO DEL TRABAJO Y DE LA SEGURIDAD SOCIALC, VOL 6, N¹2, 2015, pp. 186-195

Rodrigo Sanhueza Torres / Un limite a la responsabilidad de la empresa principal en el procedimiento de tutela laboral. Comentario a sentencia de Ilustrísima Corte de Apelaciones de Concepción.

Rupayan con Team Work Recursos Humanos Ltda. (2014): Juzgado de Letras del Trabajo de Los Ángeles, 30 de abril del 2014 (procedimiento de tutela laboral). 